\title{
Concise Synthesis of the Bacterial DNA Primase Inhibitor (+)-Sch 642305
}

\author{
Erica M. Wilson and Dirk Trauner \\ Department of Chemistry, University of California, Berkeley, CA 94720
}

\section{Supporting Information}

General Methods. All reactions were carried out under an inert $\mathrm{N}_{2}$ atmosphere in ovendried glassware. Reactions were monitored by thin-layer chromatography (TLC) which was performed using Merck® silica gel $60 \mathrm{~F}_{254}$ pre-coated plates $(0.25 \mathrm{~mm})$ and visualized by UV absorbance (254 or $366 \mathrm{~nm}$ ), potassium permanganate, or anisaldehyde stain. Flash column chromatography was carried out with EcoChrom ICN SiliTech 32-63 D 60 $\AA$ silica gel using the indicated solvent system as eluent. Methylene chloride $\left(\mathrm{CH}_{2} \mathrm{Cl}_{2}\right)$ was purified by passage over activated alumina. Tetrahydrofuran (THF) was distilled from benzophenone and sodium immediately prior to use. Benzene $(\mathrm{PhH})$, diisopropylamine $\left(i-\mathrm{Pr}_{2} \mathrm{NH}\right)$, triethylamine, and acetonitrile $\left(\mathrm{CH}_{3} \mathrm{CN}\right)$ were distilled from $\mathrm{CaH}_{2}$ immediately prior to use. $n$-Butyllithium was titrated with diphenylacetic acid prior to use. All other reagents and solvents were used without further purification from commercial sources. NMR spectra were measured on Bruker DRX-500, Av-500, AVQ400, AVB-400 and Av-300 instruments, ${ }^{1} \mathrm{H}: 500 \mathrm{MHz}, 400 \mathrm{MHz}$ or $300 \mathrm{MHz}$ and ${ }^{13} \mathrm{C}: 125 \mathrm{MHz}$ or $100 \mathrm{MHz} .{ }^{1} \mathrm{H}$ chemical shifts are reported using residual undeuterated solvent as an internal standard ( $\left.\mathrm{CHCl}_{3:} 7.26 \mathrm{ppm}, \mathrm{MeOH}: 4.78 \mathrm{ppm}\right)$. The abbreviations used for the multiplicity are: $\mathrm{s}=$ singlet, $\mathrm{d}=$ doublet, $\mathrm{t}=$ triplet. ${ }^{13} \mathrm{C}$ chemical shifts are reported using the central peak of deuterochloroform or deuteromethanol as an internal standard (77.2 and 49.0, respectively). HPLC purification was performed using a Dynamax Microsorb 60Si column $(21 \times 250 \mathrm{~mm}, 8 \mu \mathrm{m}, 60 \AA)$ with isopropanol and hexanes. IR spectra were measured with a Genesis FT-IR or Nicolaet FT-IR spectrometer by thin film on $\mathrm{NaCl}$ plates. Melting points were determined with an electrothermal apparatus and are uncorrected.

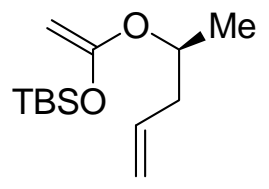

(-)-(S-Pent-4-en-2-yl)-(tert-butyldimethylsilyl)-ketenacetal (11). To a solution of LDA in THF $(50 \mathrm{~mL}, 1.22 \mathrm{M})$ at $-78^{\circ} \mathrm{C}$, was added ester $10(7.1 \mathrm{~g}, 55.4 \mathrm{mmol})$ dropwise over $15 \mathrm{~min}$. The solution was stirred at the addition temperature for $50 \mathrm{~min}$., HMPA (5.54 $\mathrm{mL}, 45.2 \mathrm{mmol}$ ) was added, and the reaction was stirred an additional $5 \mathrm{~min}$. A solution of TBSCl in n-pentane $(15 \mathrm{~mL}, 4.1 \mathrm{M})$ was added over $10 \mathrm{~min}$. The solution was left to 
stir at $-78^{\circ} \mathrm{C}$ for $1 \mathrm{~h}$, was warmed to $0^{\circ} \mathrm{C}$, and quenched with cold water $(50 \mathrm{~mL})$. The organics were extracted with n-pentane $(3 \times 50 \mathrm{~mL})$, washed with brine $(20 \mathrm{~mL})$, dried over $\mathrm{MgSO}_{4}$, and concentrated in vacuo. The crude liquid was purified via Kugelrohr distillation $\left(130^{\circ} \mathrm{C}, 0.5 \mathrm{~mm} \mathrm{Hg}\right)$ to provide 11 as a clear colorless liquid $(9.5 \mathrm{~g}, 39.0 \mathrm{mmol}$, 70\%): $[\alpha]^{25}{ }_{\mathrm{D}}-2.3$ (c 1.1, $\mathrm{CHCl}_{3}$ ); IR (NaCl) 2958, 2859, 1652, 1472, $1271 \mathrm{~cm}^{-1} ;{ }^{1} \mathrm{H}$ NMR $\left(\mathrm{CDCl}_{3}, 500 \mathrm{MHz}\right) \delta$ 5.83-5.75 (m, 1H), 5.11-5.06 (m, 2H), $4.09(\mathrm{~m}, 1 \mathrm{H}), 3.28(\mathrm{~d}$, $1 \mathrm{H}, J=2.5 \mathrm{~Hz}), 3.11(\mathrm{~d}, 1 \mathrm{H}, J=2.0 \mathrm{~Hz}), 2.47-2.40(\mathrm{~m}, 1 \mathrm{H}), 2.28-2.23(\mathrm{~m}, 1 \mathrm{H}), 1.22(\mathrm{~d}$, $3 \mathrm{H}, J=6.0 \mathrm{~Hz}), 0.93(\mathrm{~s}, 9 \mathrm{H}), 0.17(\mathrm{~s}, 6 \mathrm{H}) ;{ }^{13} \mathrm{C} \mathrm{NMR}\left(\mathrm{CDCl}_{3}, 125 \mathrm{MHz}\right) \delta 159.7,134.3$, 117.6, 73.0, 62.0, 40.4, 25.8, 18.9, 18.2, -4.3; HRMS (FAB+) calcd for $\mathrm{C}_{13} \mathrm{H}_{27} \mathrm{O}_{2} \mathrm{Si}(\mathrm{M}+$ $\left.\mathrm{H}^{+}\right)$: 243.1780 , found: 243.1787 .<smiles>C=CCC(C)OC(=O)C[C@H]1C=C(O[Sb])CC[C@@H]1[OH2+]</smiles>

(-)-S-Pent-4-en-2-yl

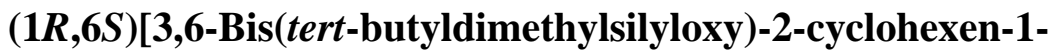
yl]acetate (12). To a solution of (4) $(3.5 \mathrm{~g}, 15.5 \mathrm{mmol})$ and TBSOTf $(0.2 \mathrm{~mL}, 0.87$ $\mathrm{mmol})$ in $\mathrm{DCM}$ at $0^{\circ} \mathrm{C}$ was added silyl ketene acetal $11(5.63 \mathrm{~g}, 23.3 \mathrm{mmol})$ in DCM in one portion. The reaction was stirred for $15 \mathrm{~min}$. then quenched by stirring with 2pyridinol $(0.08 \mathrm{~mL}, 0.87 \mathrm{mmol})$ for $15 \mathrm{~min}$. The solution was warmed to room temperature then filtered over a plug of silica gel (deactivated with $1 \%$ TEA, eluted with $10 \%$ EtOAc in hexanes). The residue was concentrated in vacuo and purified flash silica column chromatography (deactivated with $1 \%$ TEA, eluted a gradient of hexanes to $1 \%$ EtOAc in hexanes) to provide 12 as a colorless oil as a 3.7:1 mixture of syn : anti stereoisomers (5.4 g, $11.5 \mathrm{mmol}, 81 \%)$. The isomers could be separated only on an analytical scale by HPLC. Stereochemical assignments were based on NOE correlations. Syn isomer: $[\alpha]^{25}-20.2$ (c 0.26, $\left.\mathrm{CHCl}_{3}\right)$; IR (NaCl) 2957, 2930, 2858, 1737, 1667, 1640, 1472, 1463, 1379, 1260, 1181, 1098, $1015 \mathrm{~cm}^{-1} ;{ }^{1} \mathrm{H} \mathrm{NMR}\left(\mathrm{CDCl}_{3}, 500 \mathrm{MHz}\right) \delta$ 5.80-5.71 (m, 1H), 5.10-5.05 (m, 2H), 4.96 (sextet, $1 \mathrm{H}, J=6.2 \mathrm{~Hz}), 4.69(\mathrm{~d}, 1 \mathrm{H}, J=6.0$ $\mathrm{Hz}), 3.97(\mathrm{~m}, 1 \mathrm{H}), 2.71(\mathrm{~m}, 1 \mathrm{H}), 2.62(\mathrm{dd}, 1 \mathrm{H}, J=15.5,5.5 \mathrm{~Hz}), 2.35(\mathrm{dt}, 1 \mathrm{H}, J=14.0$, $7.0 \mathrm{~Hz}), 2.26(\mathrm{dt}, 1 \mathrm{H}, J=14.0,6.9 \mathrm{~Hz}), 2.11(\mathrm{dd}, 1 \mathrm{H}, J=15.5,9.3 \mathrm{~Hz}), 2.15-2.09(\mathrm{~m}$, $1 \mathrm{H}), 2.01(\mathrm{dt}, 1 \mathrm{H}, J=17.3,6.8 \mathrm{~Hz}), 1.75$ (quintet, $1 \mathrm{H}, J=6.8 \mathrm{~Hz}), 1.66-1.61(\mathrm{~m}, 1 \mathrm{H})$, $1.22(\mathrm{~d}, 3 \mathrm{H}, J=6.0 \mathrm{~Hz}), 0.90(\mathrm{~s}, 9 \mathrm{H}), 0.88(\mathrm{~s}, 9 \mathrm{H}), 0.88-0.86(\mathrm{~m}, 1 \mathrm{H}), 0.11(\mathrm{~s}, 6 \mathrm{H}), 0.05$ $(\mathrm{d}, 6 \mathrm{H}, J=5.5 \mathrm{~Hz}) ;{ }^{13} \mathrm{C} \mathrm{NMR}\left(\mathrm{CDCl}_{3}, 125 \mathrm{MHz}\right) \delta 173.2,150.7,133.9,117.8,105.5$, 70.0, 68.2, 40.5, 37.2, 36.7, 28.7, 27.3, 26.0, 25.8, 19.7, 18.3, 18.2, -4.2, -4.4, -4.4, -4.8 ; HRMS (FAB+) calcd for $\mathrm{C}_{25} \mathrm{H}_{49} \mathrm{O}_{4} \mathrm{Si}_{2}\left(\mathrm{M}+\mathrm{H}^{+}\right)$: 469.3169 , found: 469.3167 . 
<smiles>C=CCC(C)OC(=O)C[C@@H]1[C@H](O)CCC(=O)[C@@H]1OC</smiles>

S-Pent-4-en-2-yl (1RS,2RS,6S)-[6-(tert-Butyldimethylsilyloxy)-2-(2-propenyl)-3-oxocyclohex-1-yl]acetate (3). A solution of silyl enol ether (mixture of C4-C5 isomers) 12 (3.52 g, $7.5 \mathrm{mmol}$ ) and allyl bromide $(2.2 \mathrm{~mL}, 25.4 \mathrm{mmol})$ in dry THF $(80 \mathrm{~mL})$ was stirred for $20 \mathrm{~min}$. over $4 \AA \mathrm{MS}$. To the reaction solution at $-35^{\circ} \mathrm{C}$, was added TASF (2.350 g, $8.5 \mathrm{mmol}, 2 \mathrm{M}$ in DMF) dropwise. The solution was stirred at the addition temperature for $30 \mathrm{~min}$. then at $0^{\circ} \mathrm{C}$ for an additional $2 \mathrm{~h}$. The reaction was diluted with $\mathrm{H}_{2} \mathrm{O}(30 \mathrm{~mL})$ then the organics were extracted with diethyl ether $(3 \times 30 \mathrm{~mL})$, dried over $\mathrm{MgSO}_{4}$, and concentrated in vacuo. The crude product was purified by flash silica column chromatography (20:1 hexanes : EtOAc) to afford 3 (mixture of inseparable 2.7:1 C4-C5 isomers) as a clear oil (1.65 g, $4.18 \mathrm{mmol}, 56 \%)$ : IR ( NaCl) 2929, 2856, $1727,1700,1650,1250,1080 \mathrm{~cm}^{-1} ;{ }^{1} \mathrm{H} \mathrm{NMR}\left(\mathrm{CDCl}_{3}, 500 \mathrm{MHz}\right) \delta 5.80-5.70(\mathrm{~m}, 2 \mathrm{H})$, 5.11-4.94 (m, 5H), 4.179-4.17 (m, 0.73H), 4.15-4.11 (m, 0.27H), 2.70-1.99 (m, 11H), 1.86-1.83 (m, 0.74), 1.83-1.70 (m, 0.29H), 1.23-1.21 (m, 3H), $0.92(\mathrm{~s}, 6.8 \mathrm{H}), 0.89(\mathrm{~s}$, $2.2 \mathrm{H}), 0.09(\mathrm{~s}, 6 \mathrm{H}) ;{ }^{13} \mathrm{C} \mathrm{NMR}\left(\mathrm{CDCl}_{3}, 125 \mathrm{MHz}\right) \delta 211.1,172.2,135.9,133.7,118.0$, 116.8, 70.5, 67.6, 48.7, 43.5, 40.4, 36.1, 34.2, 32.7, 30.5, 26.0, 19.5, 18.2, -4.2, -4.9; HRMS (FAB+) calcd for $\mathrm{C}_{22} \mathrm{H}_{39} \mathrm{O}_{4} \mathrm{Si}\left(\mathrm{M}+\mathrm{H}^{+}\right)$: 395.2618, found: 395.2627.<smiles>CCCC1C(=O)CC[C@@H](O)[C@@H]1CC(=O)OC(C)C</smiles>

\section{(-)-\{(1R,2R,6S)-6-(tert-Butyldimethylsilyloxy)-2-[(S)-5-hydroxy-hex-2-enyl]-3-oxo-}

cyclohex-1-yl\}acetic acid lactone (13). To a solution of diene 3 (206 $\mathrm{mg}, 0.52 \mathrm{mmol})$ in DCM (100 mL), was added Grubbs II catalyst. The reaction was refluxed for $4 \mathrm{~h}$, cooled and filtered through celite. Purification of the crude residue by flash silica column chromatography (20:1 hexanes : EtOAc) afforded 13 as a white solid (120 mg, 0.34 mmol, 63\%): $\mathrm{mp} 76-78^{\circ} \mathrm{C}$; $[\alpha]^{25} \mathrm{D}-20.8$ (c 0.40, $\left.\mathrm{CHCl}_{3}\right)$; IR (NaCl) 2927, 2856, 1727 , $1700,1461,1250,1080 \mathrm{~cm}^{-1} ;{ }^{1} \mathrm{H}$ NMR $\left(\mathrm{CDCl}_{3}, 300 \mathrm{MHz}\right) \delta 5.66-5.52(\mathrm{~m}, 2 \mathrm{H}), 5.03(\mathrm{~m}$, $1 \mathrm{H}), 4.02(\mathrm{~m}, 1 \mathrm{H}), 2.94(\mathrm{bs}, 1 \mathrm{H}), 2.80-2.63(\mathrm{~m}, 3 \mathrm{H}), 2.44(\mathrm{~m}, 3 \mathrm{H}), 2.29-2.24(\mathrm{~m}, 1 \mathrm{H})$, 2.14-2.00 (m, 2H), 1.89-1.79 (m, 2H), $1.22(\mathrm{~d}, 3 \mathrm{H}, J=6.9 \mathrm{~Hz}), 0.92(\mathrm{~s}, 9 \mathrm{H}), 0.10(\mathrm{~s}, 3 \mathrm{H})$, $0.09(\mathrm{~s}, 3 \mathrm{H}) ;{ }^{13} \mathrm{C} \mathrm{NMR}\left(\mathrm{CDCl}_{3}, 125 \mathrm{MHz}\right) \delta 210.5,172.9,132.1,123.8,71.6,68.9,50.6$, 43.0, 41.8, 35.1, 31.8, 29.4, 26.0, 24.2, 18.2, 18.0, -4.2, -4.7; HRMS (FAB+) calcd for $\mathrm{C}_{20} \mathrm{H}_{34} \mathrm{LiO}_{4} \mathrm{Si}\left(\mathrm{M}+\mathrm{Li}^{+}\right)$: 373.2386, found: 373.2396 . 
<smiles>CC1CCCC[C@H](CC(=O)OC(C)C)[C@@H](O[Sb])C1</smiles>

\section{$(-)-\{(1 R, 2 R, 6 S)-6-(t e r t-B u t y l d i m e t h y l s i l y l o x y)-2-[(S)-5-h y d r o x y h e x y l]-3-0 x 0-$}

cyclohex-1-yl\}acetic acid lactone (14). To a solution of $13(113 \mathrm{mg}, 0.31 \mathrm{mmol})$ in EtOAc $(10 \mathrm{~mL})$ was added $5 \% \mathrm{Pd} / \mathrm{C}(100 \mathrm{mg}, 0.048 \mathrm{mmol})$. The flask was purged with $\mathrm{H}_{2}$ several times and was left to stir at room temperature under an atmosphere of $\mathrm{H}_{2}$ for 2 $\mathrm{h}$. The reaction mixture was filtered over celite and concentrated in vacuo to provided $\mathbf{1 4}$ as white needles (108 mg, $0.29 \mathrm{mmol}, 95 \%)$ : $\mathrm{mp} 100-101^{\circ} \mathrm{C} ;[\alpha]^{25} \mathrm{D}-22.2$ (c 0.37 , $\left.\mathrm{CHCl}_{3}\right)$; IR $(\mathrm{NaCl}) 2955,2857,1724,1700,1462,1253,1079 \mathrm{~cm}^{-1} ;{ }^{1} \mathrm{H} \mathrm{NMR}\left(\mathrm{CDCl}_{3}\right.$, $500 \mathrm{MHz}) \delta 5.06(\mathrm{~m}, 1 \mathrm{H}), 4.02(\mathrm{~m}, 1 \mathrm{H}), 2.67(\mathrm{td}, 1 \mathrm{H}, J=14.5,6.5 \mathrm{~Hz}), 2.58-2.45(\mathrm{~m}$, 4H), $2.20(\mathrm{~m}, 1 \mathrm{H}), 2.10(\mathrm{~m}, 1 \mathrm{H}), 2.01(\mathrm{~m}, 2 \mathrm{H}), 1.85-1.79(\mathrm{~m}, 3 \mathrm{H}), 1.36-1.25(\mathrm{~m}, 3 \mathrm{H})$, $1.25(\mathrm{~d}, 3 \mathrm{H}, J=7.0 \mathrm{~Hz}), 0.91(\mathrm{~s}, 9 \mathrm{H}), 0.91(\mathrm{~m}, 1 \mathrm{H}), 0.10(\mathrm{~s}, 3 \mathrm{H}), 0.08(\mathrm{~s}, 3 \mathrm{H}) ;{ }^{13} \mathrm{C} \mathrm{NMR}$ $\left(\mathrm{CDCl}_{3}, 125 \mathrm{MHz}\right) \delta 211.0,171.8,73.2,71.1,50.2,41.0,40.4,35.3,32.1,29.5,26.0$, 23.3, 23.0, 21.7, 18.4, 18.2, -4.2, -4.7; HRMS (FAB+) calcd for $\mathrm{C}_{20} \mathrm{H}_{37} \mathrm{O}_{4} \mathrm{Si}\left(\mathrm{M}+\mathrm{H}^{+}\right)$: 369.2461, found: 369.2453 .

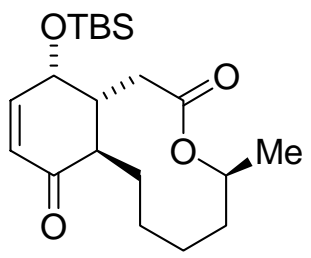

(+)-O-(tert-Butyldimethylsilyl)Sch 642305 (15). To a solution of $14(46.6 \mathrm{mg}, 0.13$ $\mathrm{mmol})$ in dry THF $(0.8 \mathrm{~mL})$ at $-78^{\circ} \mathrm{C}$ was added TESCl $(24.1 \mathrm{mg}, 0.16 \mathrm{mmol})$ in THF $(0.2 \mathrm{~mL})$. The reaction was stirred for $30 \mathrm{~min}$. then loaded directly on a plug of silica gel eluting with $4: 1$ hexanes : EtOAc and concentrated in vacuo. The TES enol ether was redissolved in $\mathrm{CH}_{3} \mathrm{CN}(5 \mathrm{~mL})$ to which was added $\mathrm{Pd}(\mathrm{OAc})_{2}(157 \mathrm{mg}, 0.7 \mathrm{mmol})$. The reaction mixture stirred at room temperature for $24 \mathrm{hrs}$ then was filtered through a plug of celite and concentrated. Purification of the crude residue by flash silica column chromatography ( $4: 1$ hexanes : EtOAc) afforded $\mathbf{1 5}$ as a white solid $(28.1 \mathrm{mg}, 0.08$ mmol, 61\%): $[\alpha]^{25}{ }_{\mathrm{D}}+52.1$ (c $\left.0.48, \mathrm{CHCl}_{3}\right)$; IR (NaCl) 2955, 1725, 1679, 1462, 1251, $1085,1034,1006 \mathrm{~cm}^{-1} ;{ }^{1} \mathrm{H}$ NMR $\left(\mathrm{CDCl}_{3}, 400 \mathrm{MHz}\right) \delta 6.85(\mathrm{dd}, 1 \mathrm{H}, J=10.0,5.6 \mathrm{~Hz})$, $5.97(\mathrm{~d}, 1 \mathrm{H}, J=10.0 \mathrm{~Hz}), 5.10-5.08(\mathrm{~m}, 1 \mathrm{H}), 4.22(\mathrm{dd}, 1 \mathrm{H}, J=5.6,3.2 \mathrm{~Hz}), 2.85-2.78$ $(\mathrm{m}, 1 \mathrm{H}), 2.74-2.70(\mathrm{~m}, 1 \mathrm{H}), 2.62-2.55(\mathrm{~m}, 1 \mathrm{H}), 2.51-2.46(\mathrm{~m}, 1 \mathrm{H}), 2.25-2.09(\mathrm{~m}, 2 \mathrm{H})$, 1.84-1.76 (m, 1H), 1.65-1.56 (m, 1H), 1.39-1.32 (m, 1H), $1.26(\mathrm{~d}, 4 \mathrm{H}, J=6.8 \mathrm{~Hz}), 0.87$ (s, 9H), 0.11 (s, 3H), 0.07 (s, 3H); ${ }^{13} \mathrm{C}$ NMR $\left(\mathrm{CDCl}_{3}, 100 \mathrm{MHz}\right) \delta 200.6,171.7,146.9$, 130.2, 73.3, 67.7, 46.7, 39.4, 37.5, 29.5, 25.9, 22.9, 21.7, 18.3, 18.2, -3.7, -4.6; HRMS $(\mathrm{FAB}+)$ calcd for $\mathrm{C}_{20} \mathrm{H}_{34} \mathrm{LiO}_{4} \mathrm{Si}\left(\mathrm{M}+\mathrm{Li}^{+}\right)$: 373.2386 , found: 373.2389 . 


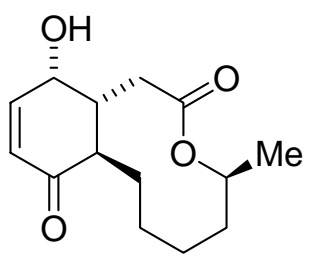

(+)-Sch 642305 (1). To a solution of TBS ether $15(24 \mathrm{mg}, 0.07 \mathrm{mmol})$ in THF ( $2 \mathrm{~mL})$ at room temperature, was added a solution of TBAF $(0.79 \mathrm{~mL}$ of a $1 \mathrm{M}$ sol. in THF, 0.79 $\mathrm{mmol}$ ) and acetic acid $(47 \mathrm{mg}, 0.79 \mathrm{mmol})$. The reaction was stirred for $12 \mathrm{~h}$ then poured into saturated $\mathrm{NH}_{4} \mathrm{Cl}(2 \mathrm{~mL})$ and extracted with ether $(3 \times 4 \mathrm{~mL})$. The organics were washed with $\mathrm{NaHCO}_{3 \text { sat., }}$ brine $(3 \mathrm{~mL})$, dried over $\mathrm{MgSO} 4$, and were concentrated in vacuo. The crude material was purified by flash silica column chromatography $(2: 1$ hexanes : EtOAc) to afford 1 as a white solid (12 $\mathrm{mg}, 0.05 \mathrm{mmol}, 73 \%)$ : $[\alpha]^{25}+76.1(\mathrm{c}$ 0.92, MeOH); IR ( NaCl) 3423, 2917, 2850, 1720, 1676, 1460, 1386, 1279, 1249, 1202, 1076, $1061 \mathrm{~cm}^{-1}$; ${ }^{1} \mathrm{H}$ NMR (MeOD, $\left.500 \mathrm{MHz}\right) \delta 7.04(\mathrm{dd}, 1 \mathrm{H}, J=10.0,5.5 \mathrm{~Hz}), 5.97(\mathrm{~d}$, $1 \mathrm{H}, J=10.0 \mathrm{~Hz}$ ), $5.06(\mathrm{~m}, 1 \mathrm{H}), 4.23(\mathrm{dd}, 1 \mathrm{H}, J=5.5,3.5 \mathrm{~Hz}$ ), 2.83 (tdd, $1 \mathrm{H}, J=11.5$, $3.52 .4 \mathrm{~Hz}), 2.69(\mathrm{dd}, 1 \mathrm{H}, J=17.0,2.5 \mathrm{~Hz}), 2.66(\mathrm{dt}, 1 \mathrm{H}, J=11.5,4.0 \mathrm{~Hz}), 2.54(\mathrm{dd}, 1 \mathrm{H}$, $J=17.0,11.5 \mathrm{~Hz}), 2.21-2.10(\mathrm{~m}, 2 \mathrm{H}), 1.89-1.82(\mathrm{~m}, 1 \mathrm{H}), 1.61-1.53(\mathrm{~m}, 1 \mathrm{H}), 1.44-1.21$ (m, 3H), $1.29(\mathrm{~d}, 3 \mathrm{H}, J=6.5 \mathrm{~Hz}), 1.10(\mathrm{ddd}, 1 \mathrm{H}, J=14.8,11.0,3.5 \mathrm{~Hz}) ;{ }^{13} \mathrm{C}$ NMR $(\mathrm{MeOD}, 125 \mathrm{MHz}) \delta 202.3,173.7,149.4,130.6,74.7,67.1,47.7,39.7,37.8,30.7,24.2$, 24.1, 22.6, 18.6; HRMS $(\mathrm{FAB}+)$ calcd for $\mathrm{C}_{14} \mathrm{H}_{21} \mathrm{O}_{4}\left(\mathrm{M}+\mathrm{H}^{+}\right)$: 253.1440, found: 253.1443 . 


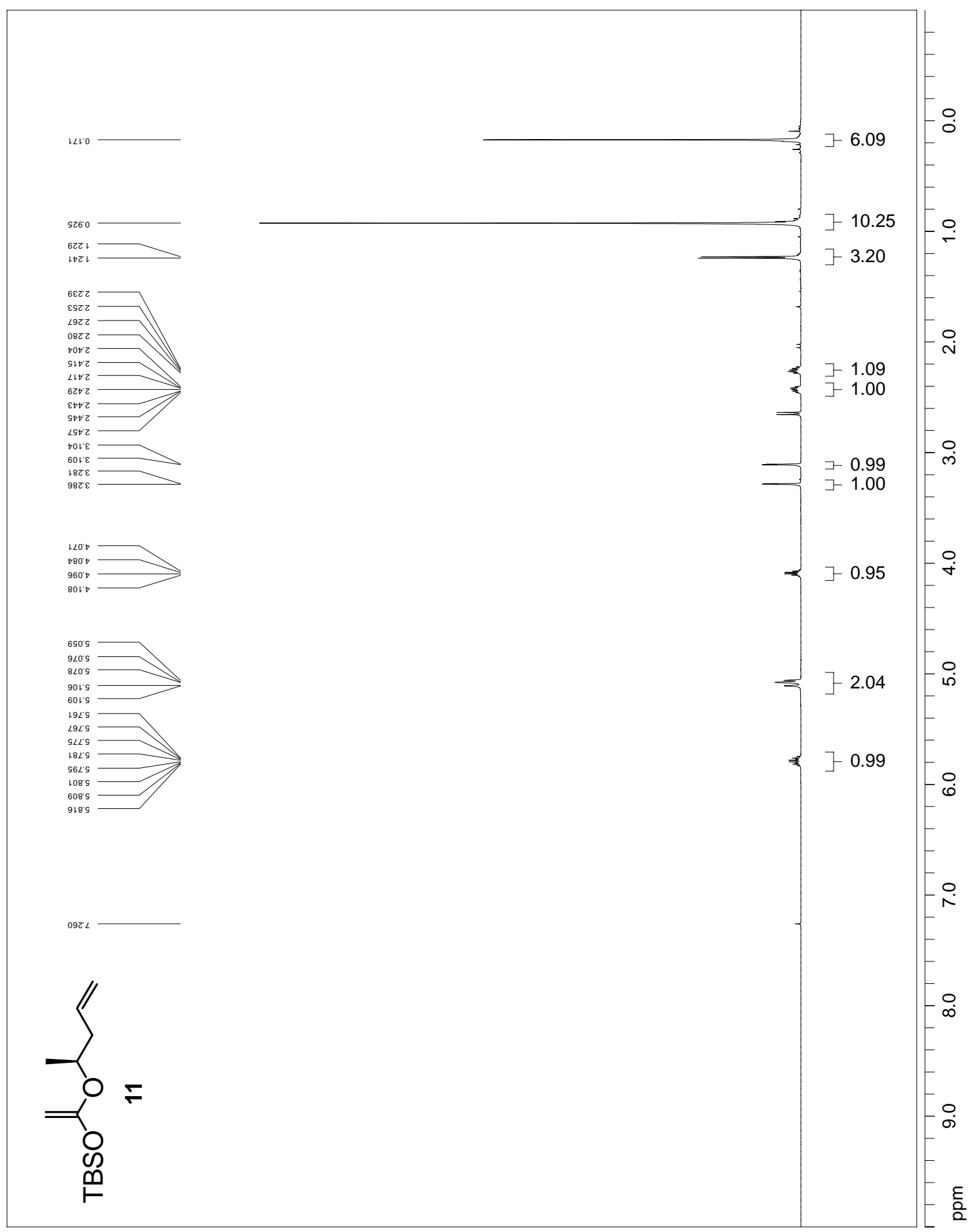




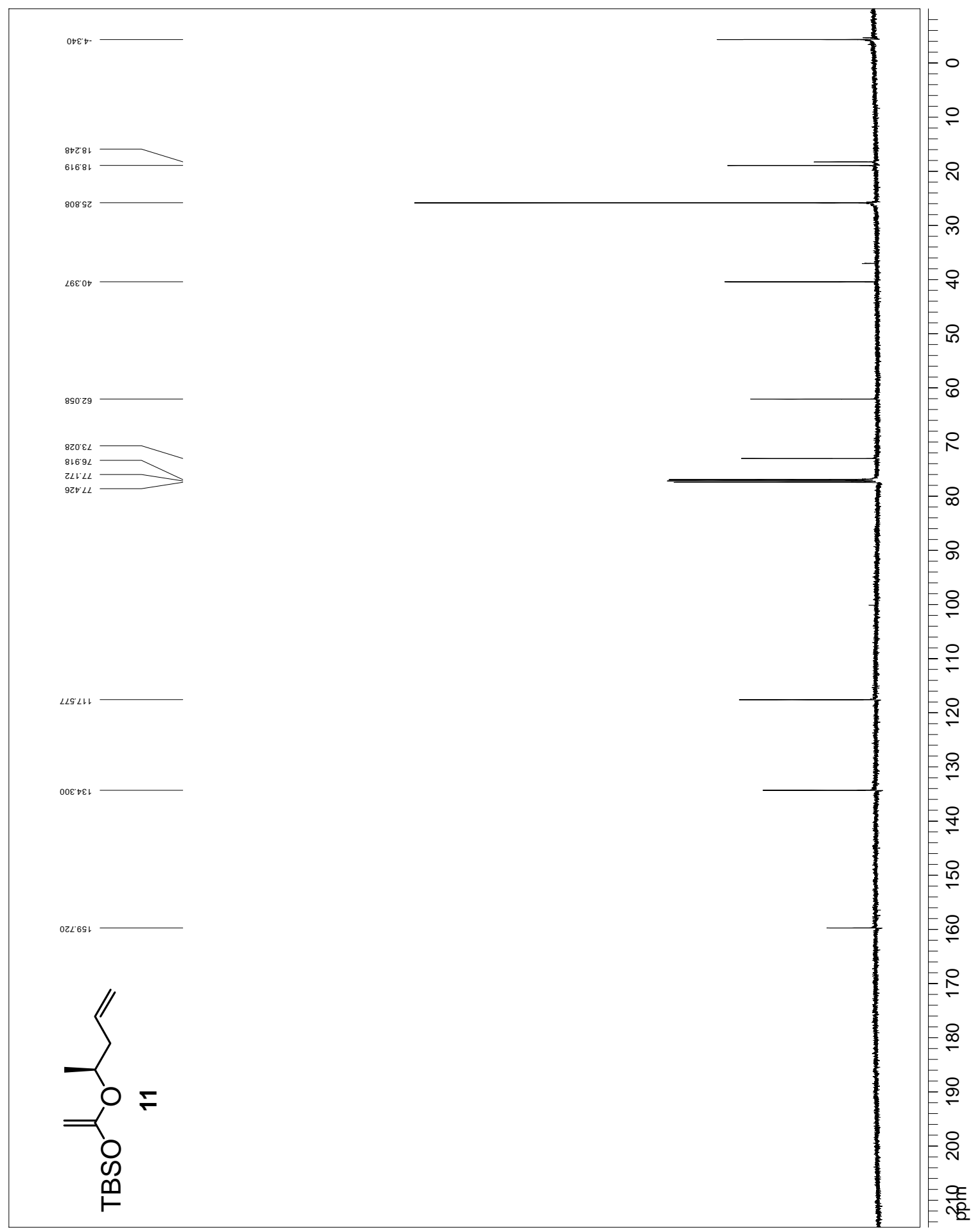




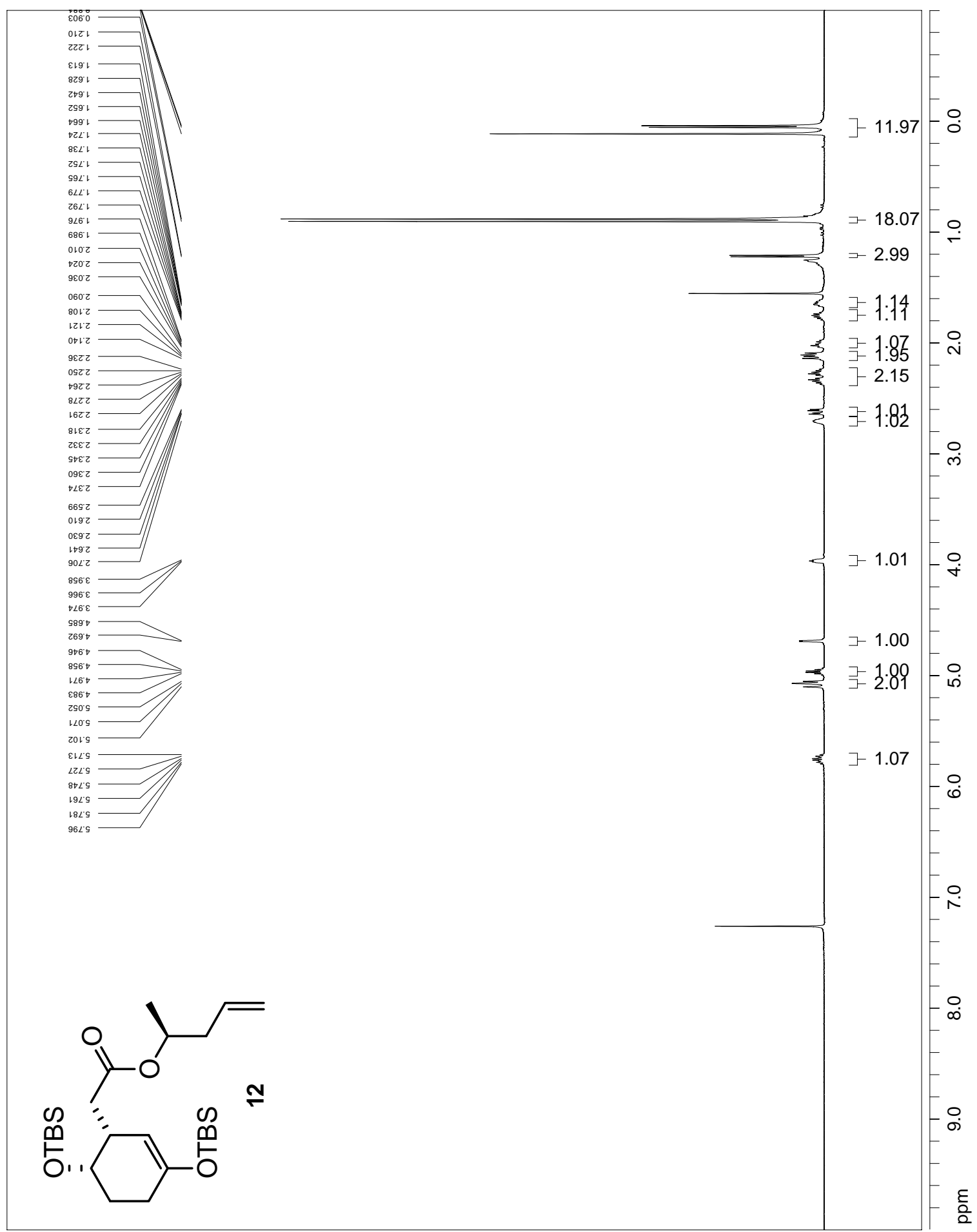




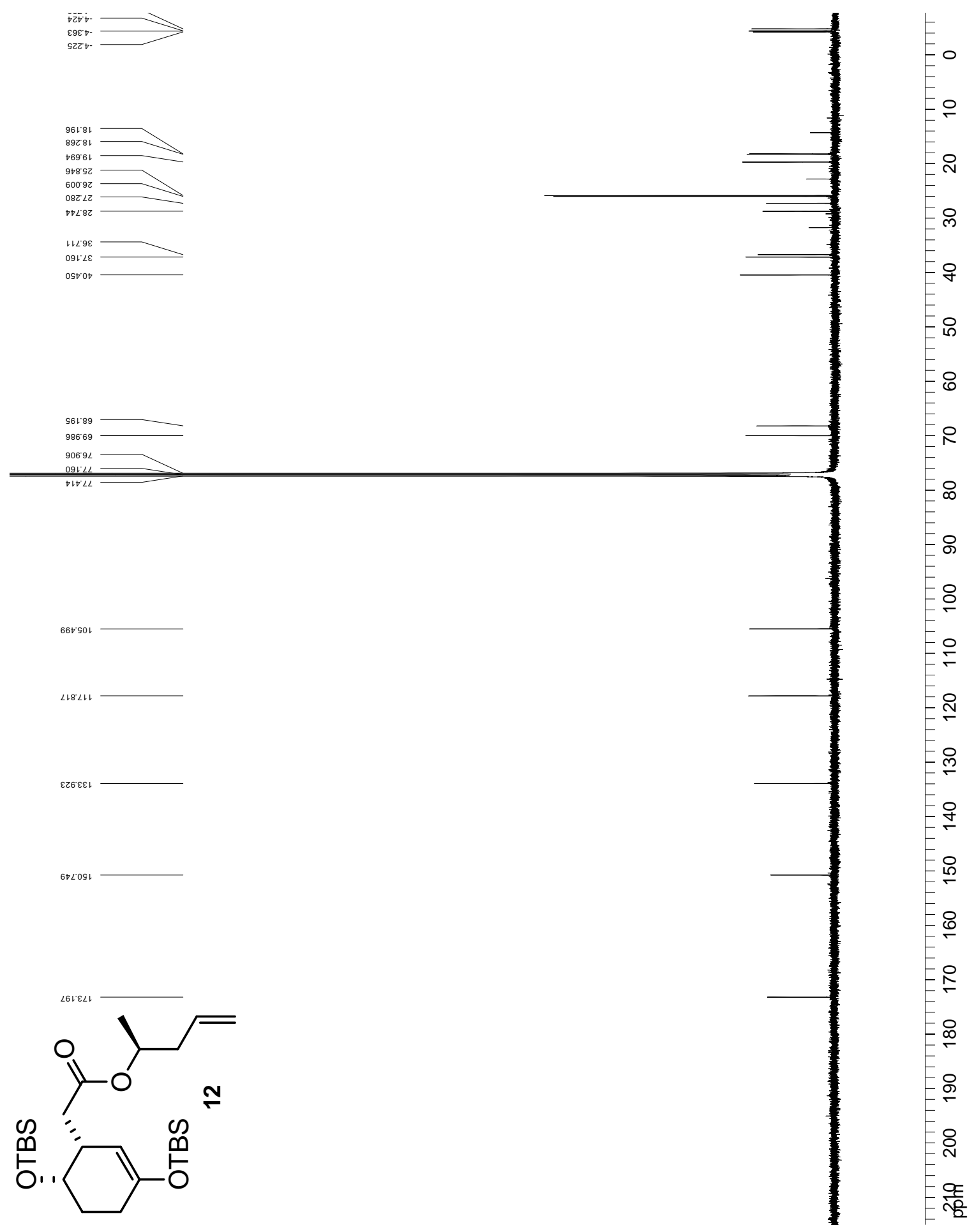




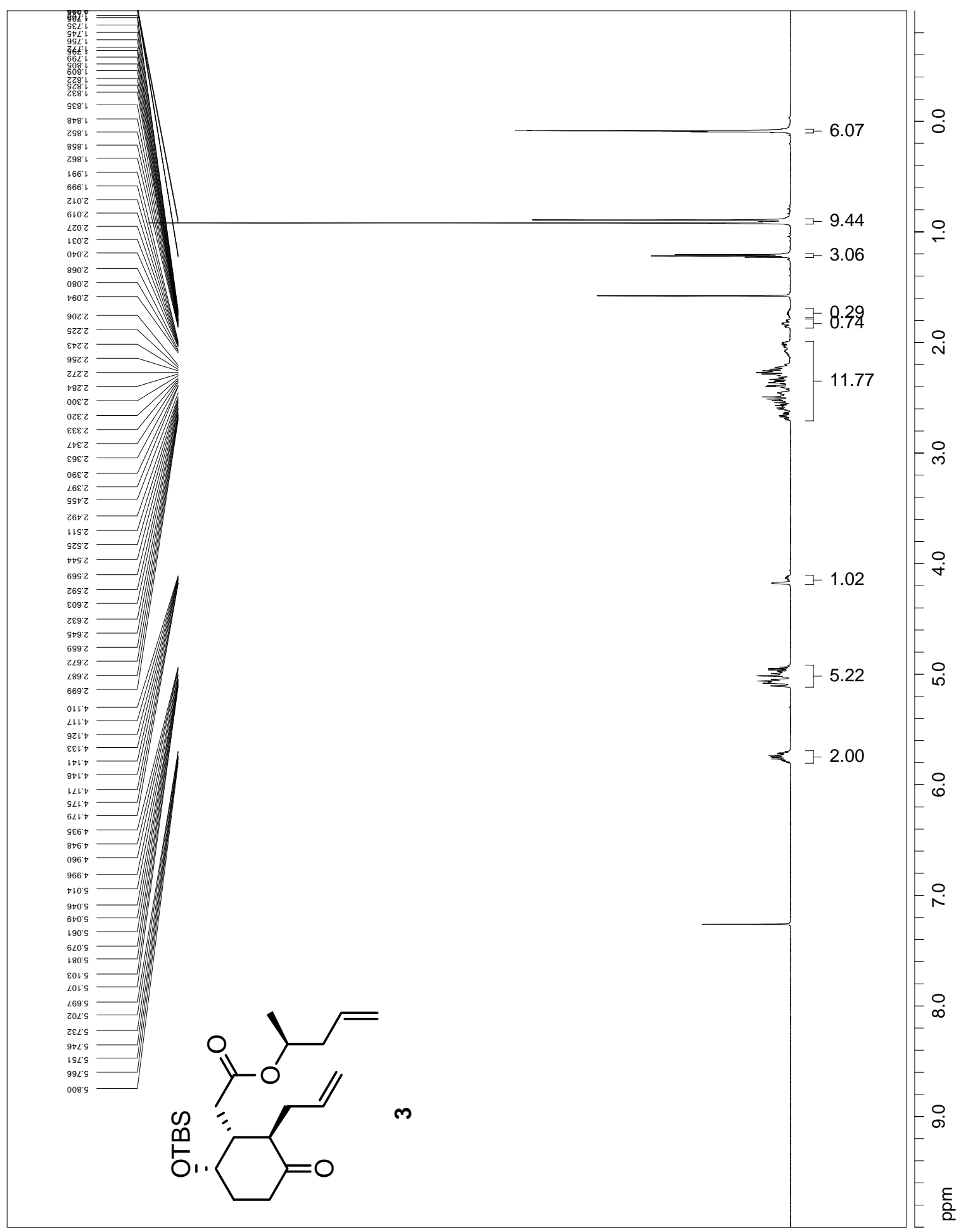




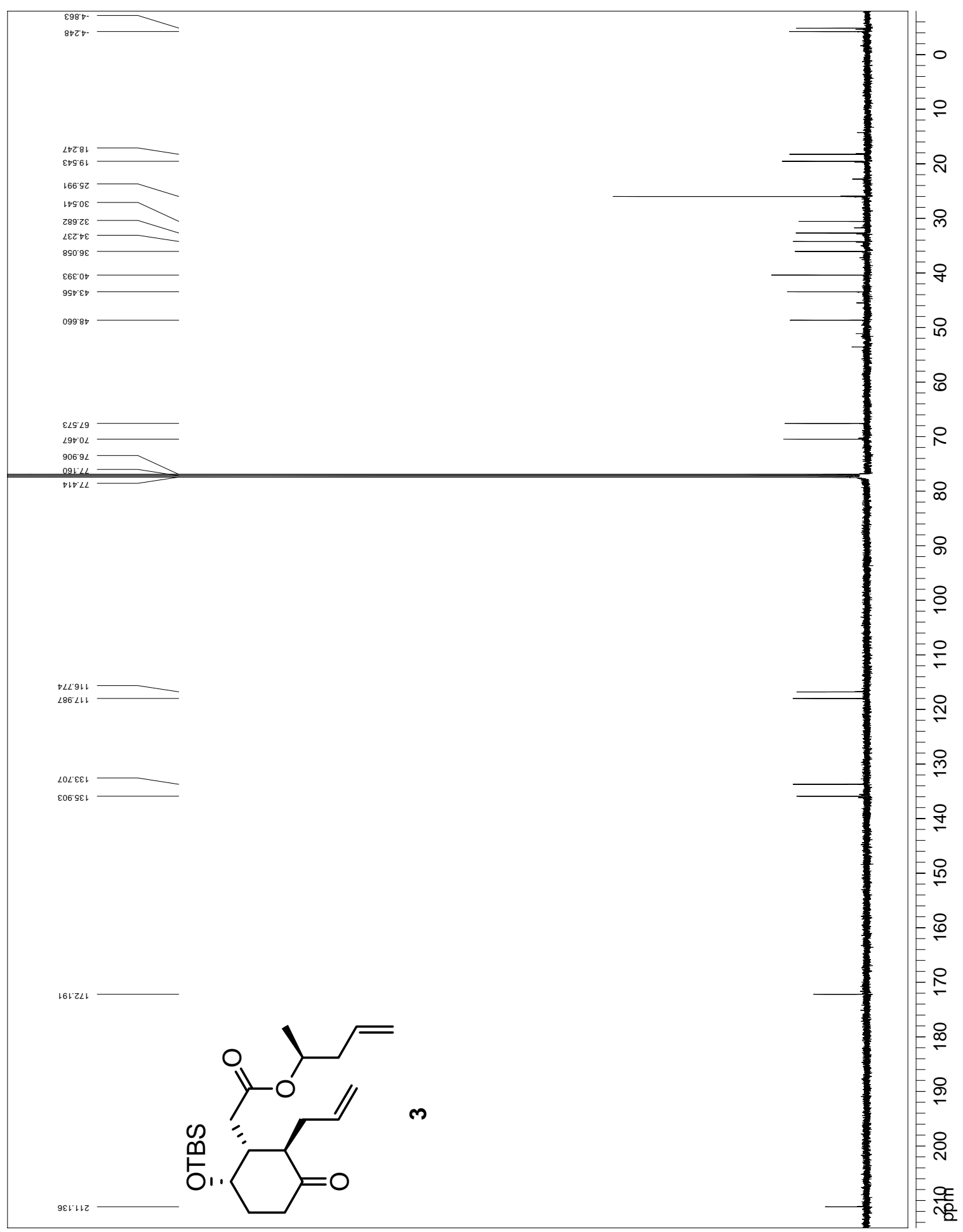




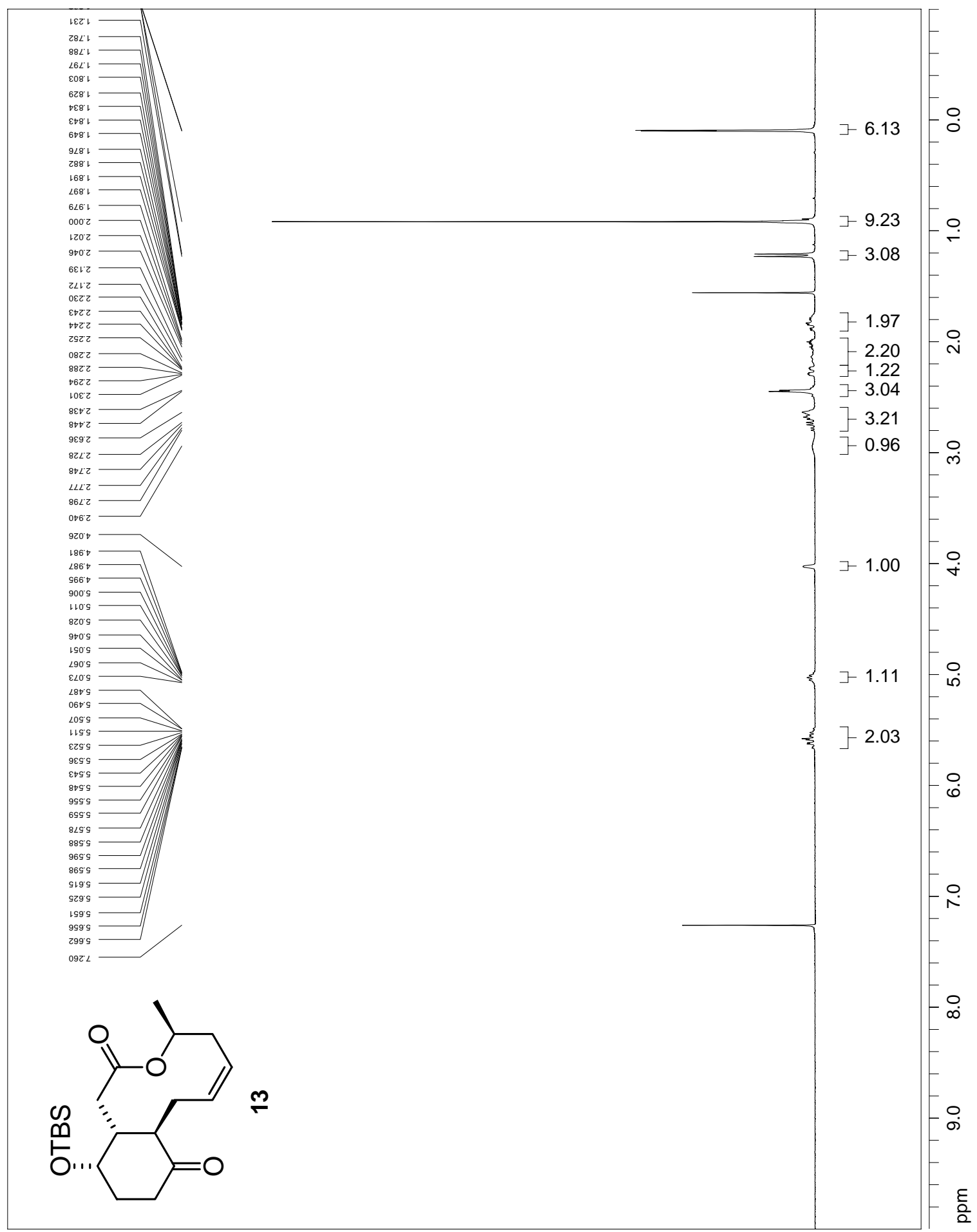




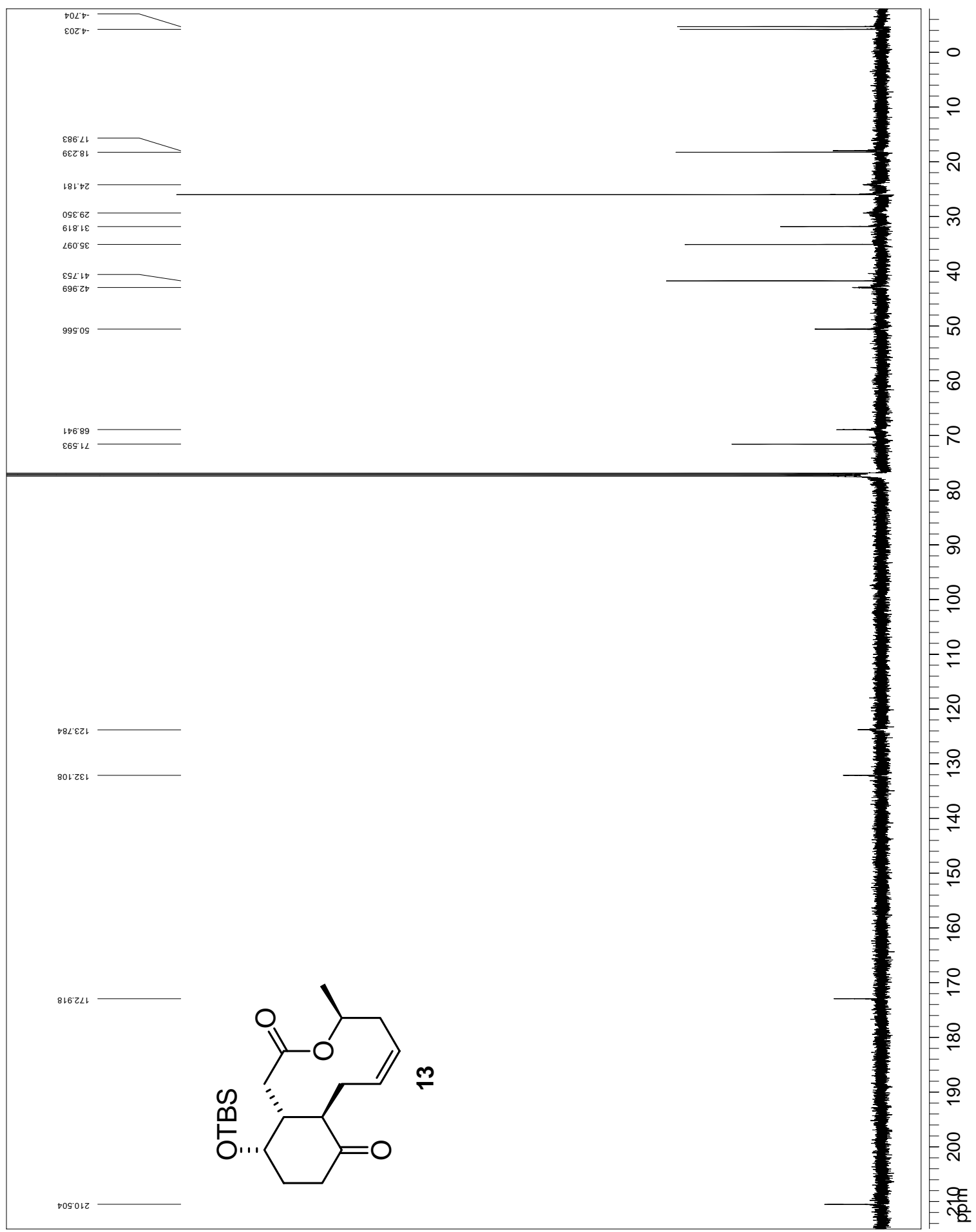




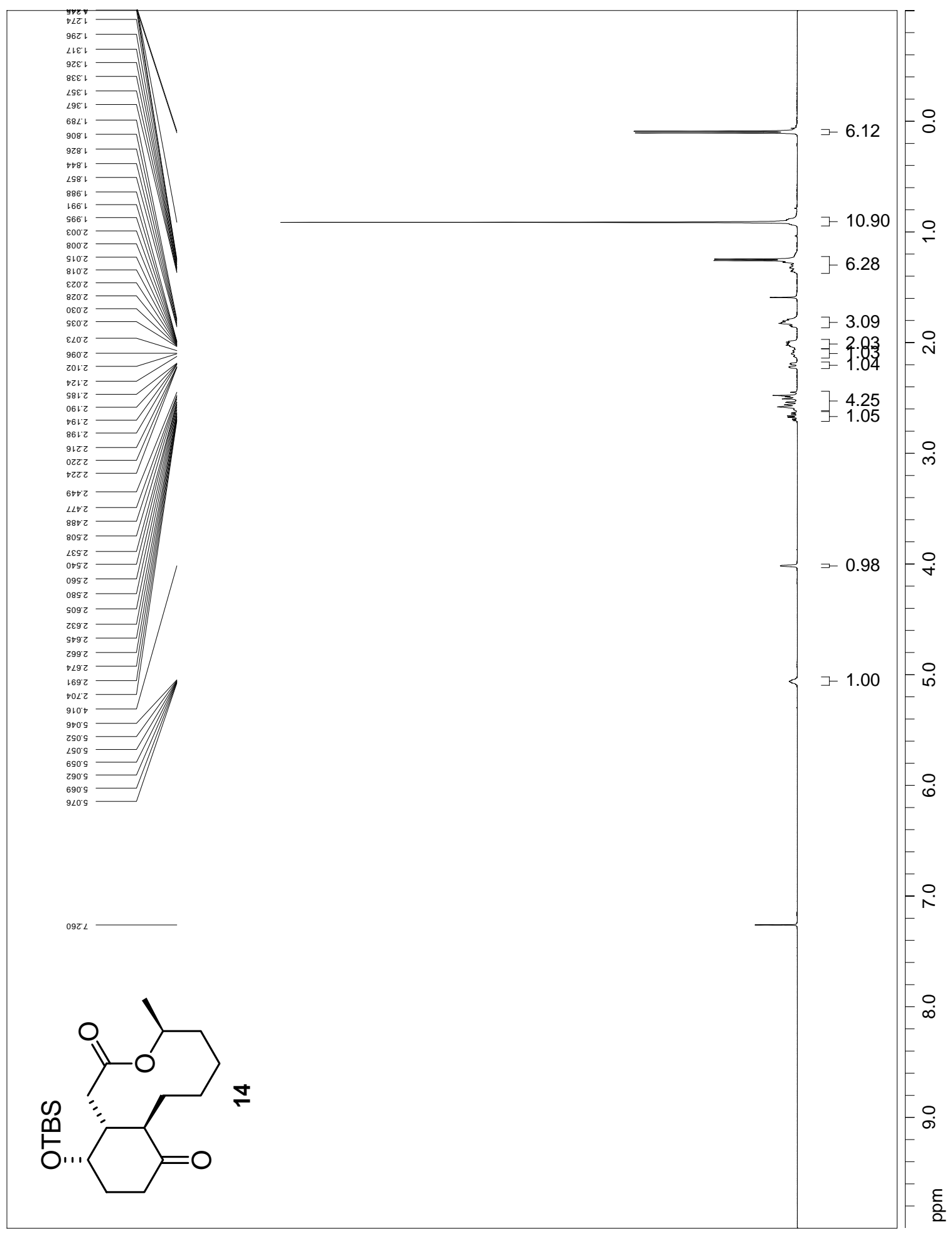




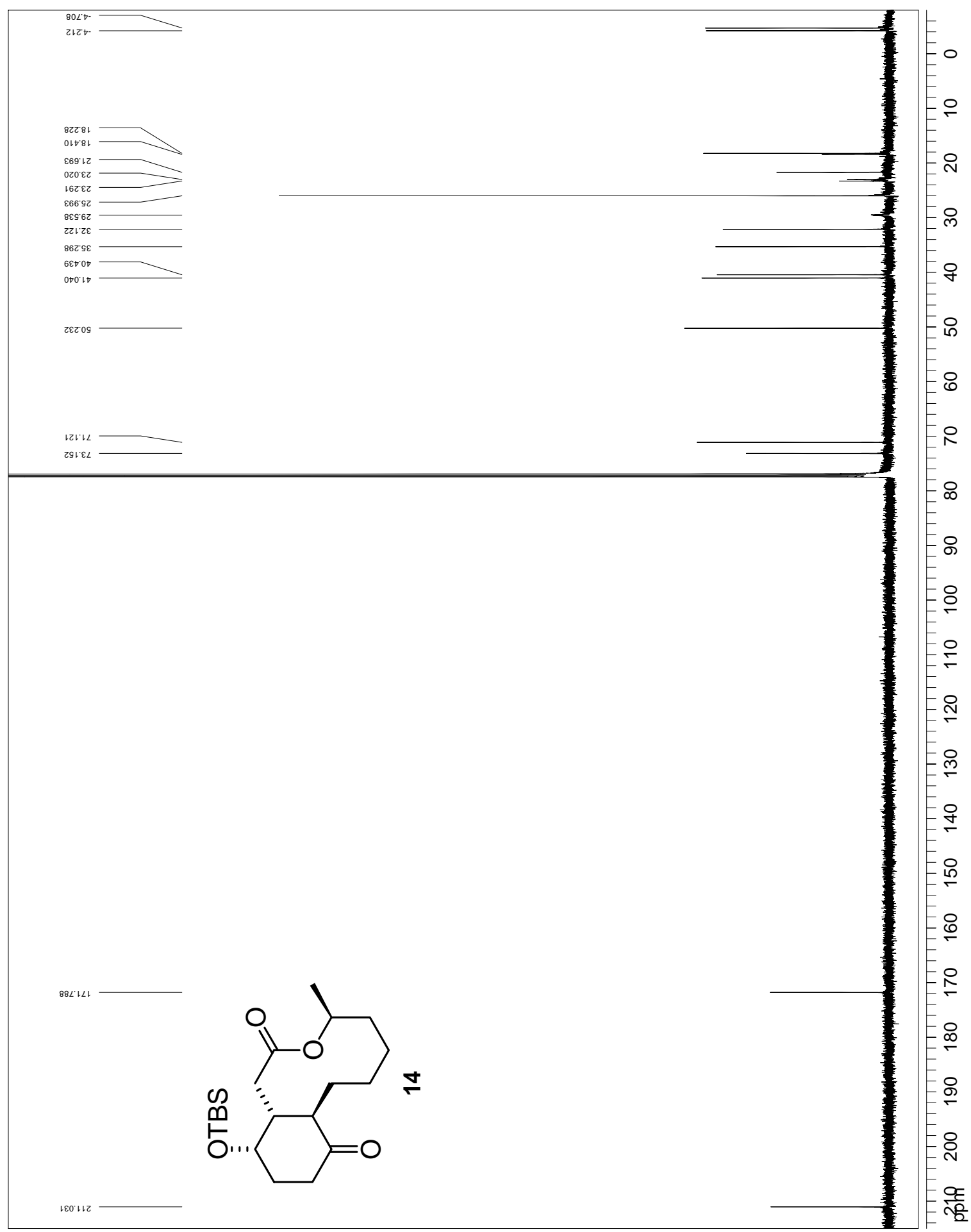




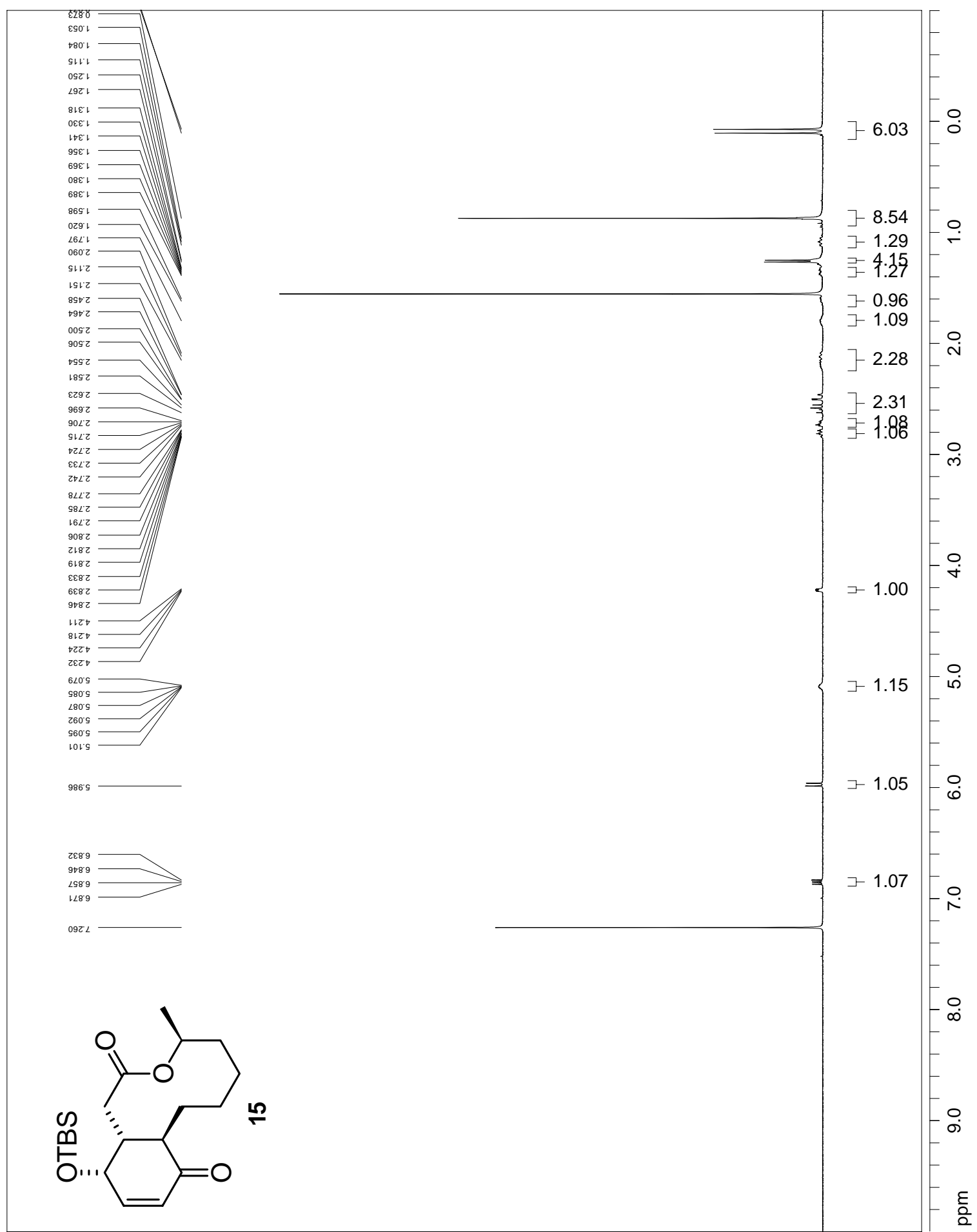




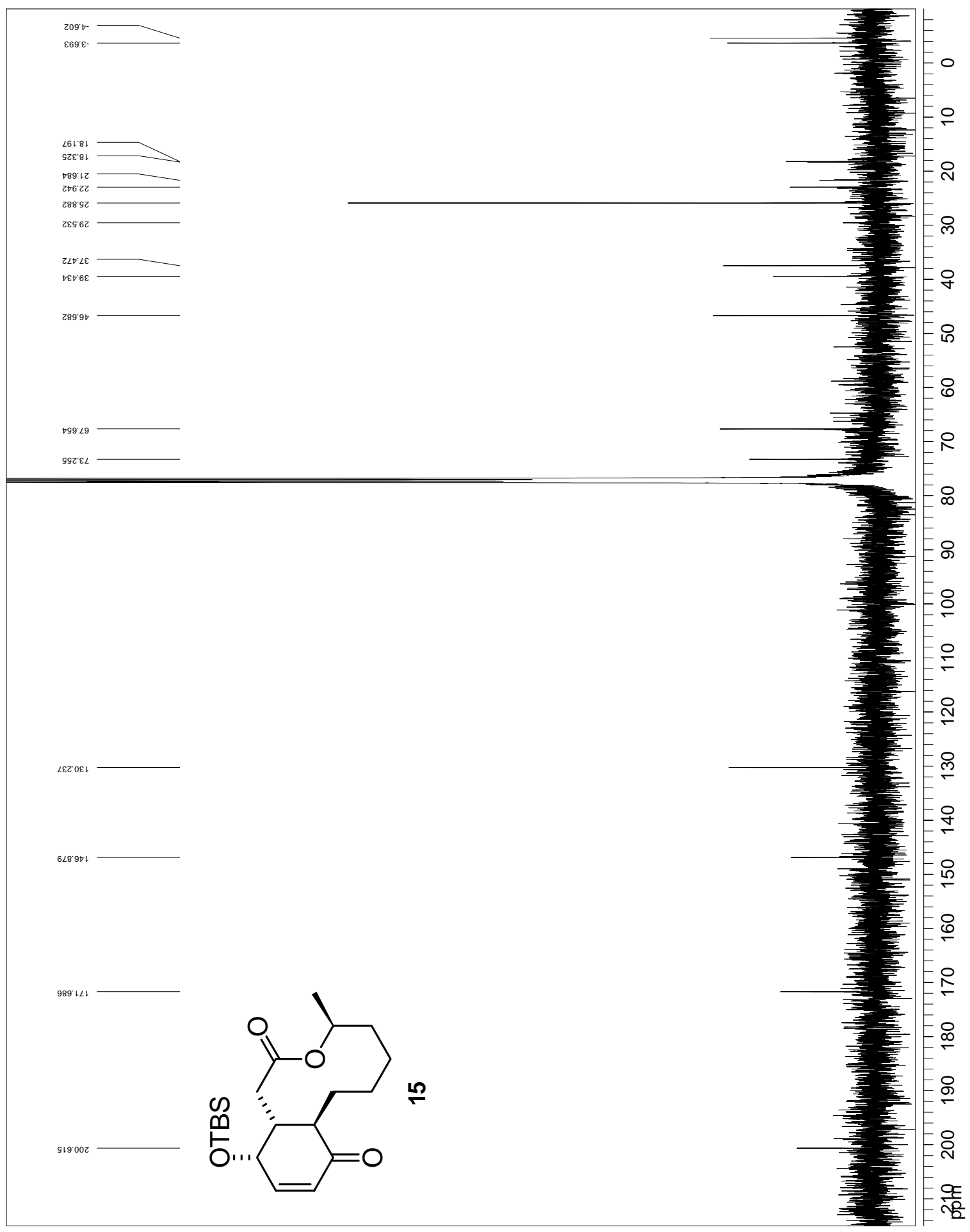




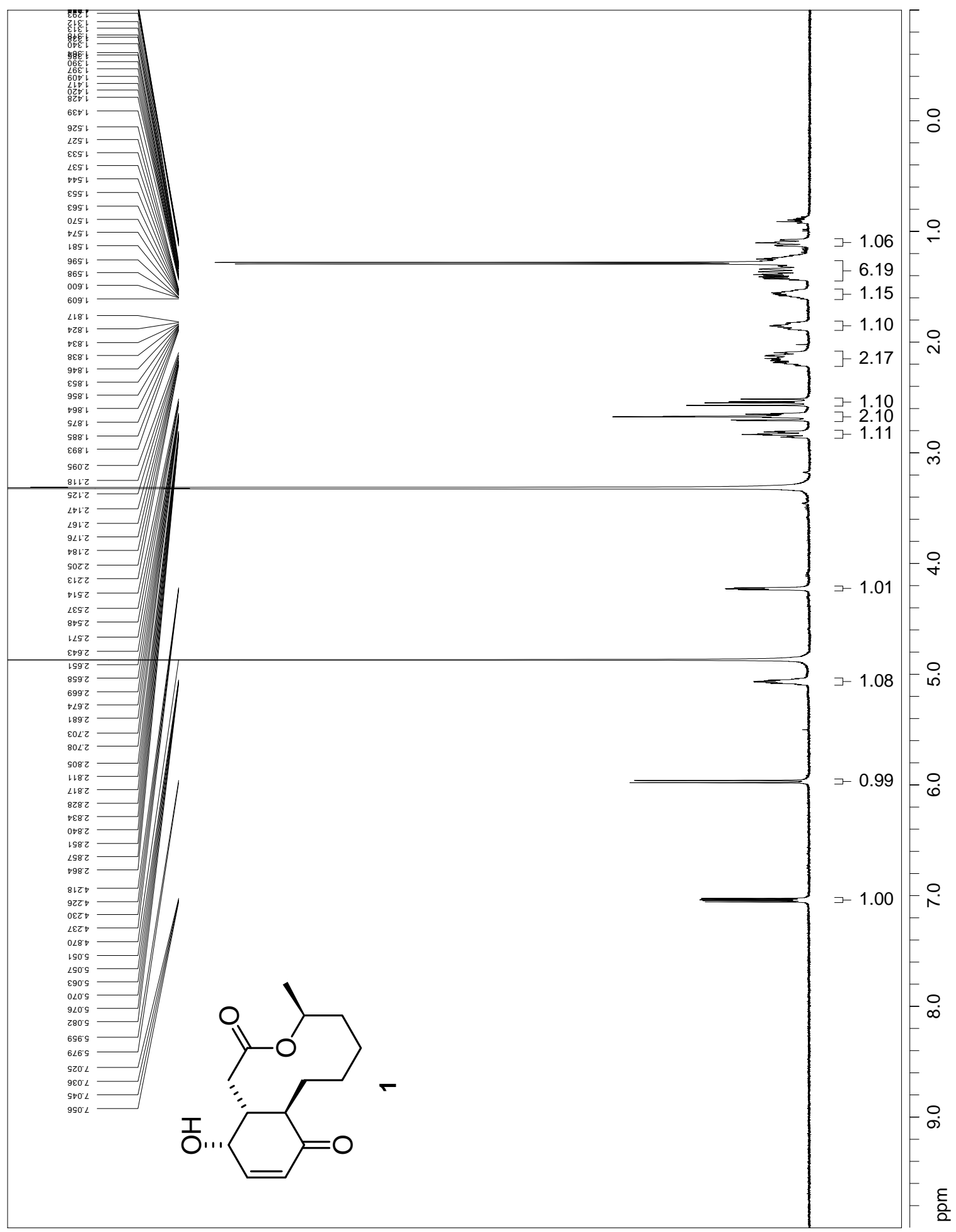




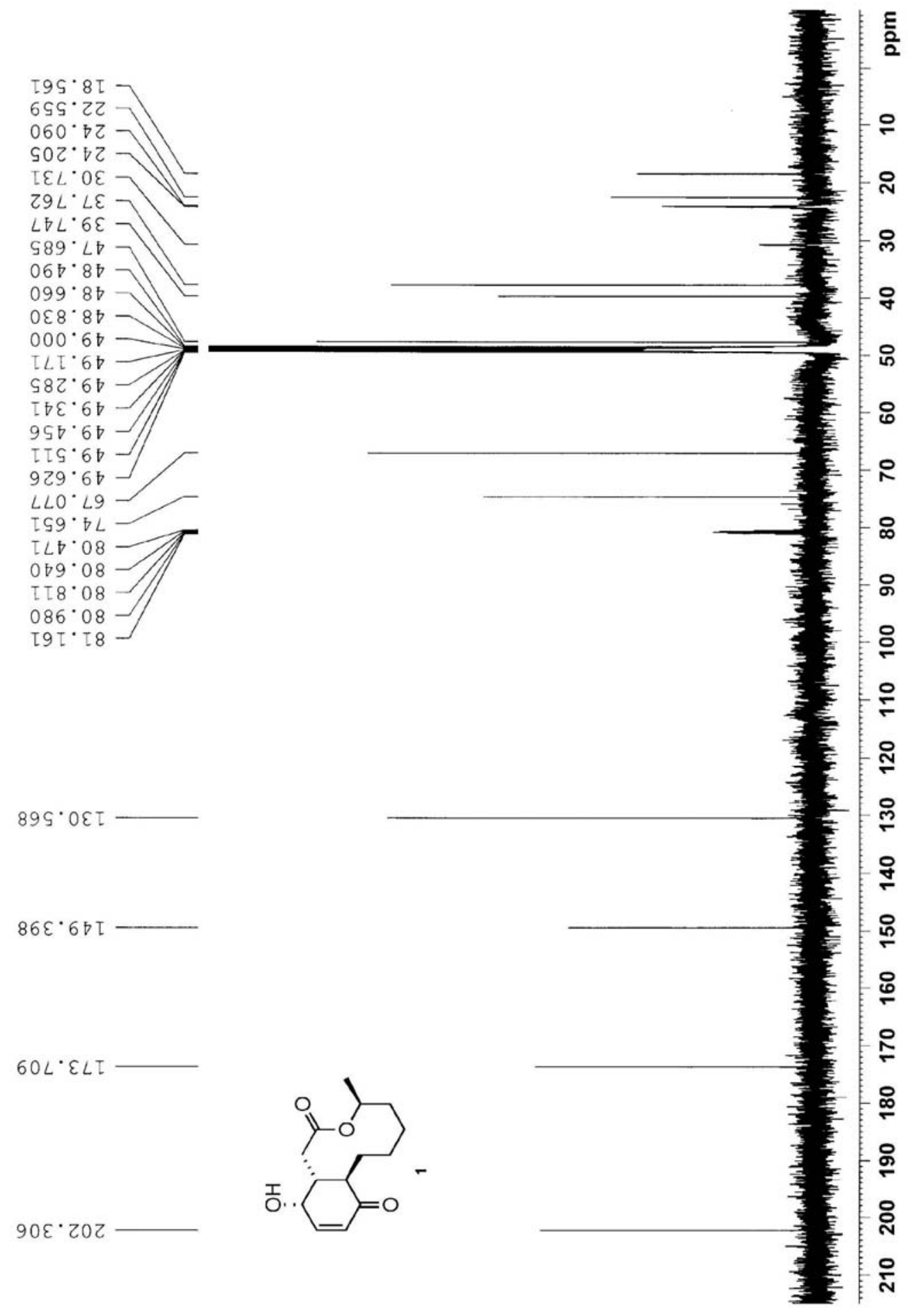

